\title{
Polymorphism in the promoter region of the NFKBIA gene is rare in Swedish and Chinese colorectal cancer patients and controls
}

\author{
ANDREAS LEWANDER ${ }^{1}$, GUNNAR ARBMAN ${ }^{2}$ and XIAO FENG SUN ${ }^{1}$ \\ ${ }^{1}$ Department of Oncology, Institute of Clinical and Experimental Medicine, University of Linköping, \\ Linköping; ${ }^{2}$ Department of Surgery in Östergötland, Norrköping, Sweden
}

Received February 11, 2009; Accepted August 25, 2009

DOI: $10.3892 / \mathrm{mmr} \_00000220$

\begin{abstract}
To investigate whether a -708ins/del8 polymorphism in the promoter region of the NFKBIA gene is related to colorectal cancer risk and clinicopathological variables, we genotyped 92 Swedish and 93 Chinese patients as well as 174 Swedish and 159 Chinese healthy controls by polymerase chain reaction-single stranded conformation polymorphism and DNA sequencing. The -708/del8 polymorphism was found in two Swedish patients and eight Swedish controls, but was absent in the Chinese population. However, among the Chinese population we found other mutations in three patients and in one control. In conclusion, the -708ins/del8 polymorphism is too rare to have a major impact on colorectal cancer incidence in the two populations.
\end{abstract}

\section{Introduction}

Nuclear factor- $\kappa \mathrm{B}(\mathrm{NF}-\kappa \mathrm{B})$ represents a group of transcription factors involved in immune response, cell adhesion, differentiation, proliferation, angiogenesis and apoptosis. $\mathrm{NF}-\kappa \mathrm{B}$ homodimers and heterodimers in human cells are normally kept inactive in the cytoplasm by inhibitory kappa $\mathrm{B}$

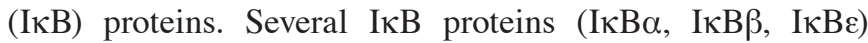
have been identified. $\mathrm{I} \kappa \mathrm{B} \alpha$ is responsible for strong negative feedback that allows for a fast turn-off of the NF- $\kappa \mathrm{B}$ response, whereas $\mathrm{I} \kappa \mathrm{B} \beta$ and $-\varepsilon$ apparently reduce oscillation and stabilize $\mathrm{NF}-\kappa \mathrm{B}$ responses during longer stimulations (1). In response to many NF- $\kappa \mathrm{B}$ activating stimuli, the $\mathrm{I} \kappa \mathrm{B} \alpha$ proteins become phosphorylated in two serine residues located within the N-terminal region. Phosphorylation of the I $\mathrm{B}$ proteins results in rapid ubiquitination and subsequent proteolysis by the 26S proteosome. Proteosome-dependent degradation of $\mathrm{I} \kappa \mathrm{B}$ proteins releases NF- $\kappa \mathrm{B}$ dimers, allowing NF- $\kappa \mathrm{B}$ to

Correspondence to: Professor Xiao-Feng Sun, Department of Oncology, Institute of Clinical and Experimental Medicine, University of Linköping, SE-581 85 Linköping, Sweden

E-mail: xiao-feng.sun@liu.se

Key words: NFKBIA, polymorphism, colorectal neoplasm, polymerase chain reaction-single stranded conformation polymorphism, DNA sequencing accumulate in the nucleus and inducing the expression of specific target genes (2).

Several lines of evidence have been presented connecting defective I $\kappa \mathrm{B}$ function to cancer development. Overexpression or constitutive activation of NF- $\mathrm{KB}$ has been found in several types of cancer, including colorectal cancer. Constitutive activation

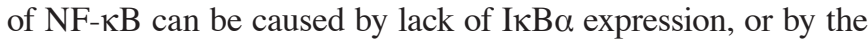
expression of non-functional I $\kappa \mathrm{B} \alpha$. Studies have also shown that the inhibition of $\mathrm{I} \kappa \mathrm{B} \alpha$ phosphorylation or degradation is linked to the inhibition of $\mathrm{NF}-\kappa \mathrm{B}$, and that this leads to decreased cancer cell growth and increased apoptosis. In a study on prostate cancer patients, it was found that the expression of $\mathrm{I} \kappa \mathrm{B}$ was decreased in this type of cancer. It appears that the correct function of $\mathrm{I} \kappa \mathrm{B}$ is necessary for suppressing the oncogenic potential of NF- $\mathrm{KB}$. Defects in the expression of $\mathrm{I} \kappa \mathrm{B}$ may be a risk factor for cancer development (3).

In a previous study, we revealed that a polymorphism in the NFKB1 gene promoter region increases the risk of colorectal cancer among Swedish unselected and sporadic colorectal cancer patients (4). This polymorphism decreases promoter activity in vitro and has no effect on protein structure. The increased risk is probably due to altered transcription of the gene. Our group also investigated an $A \rightarrow G$ variation in the 3 ' untranslated region (UTR) of the NFKBIA gene in a Chinese and a Swedish population. We found that Chinese individuals $\geq 50$ years of age carrying the AG genotype of NFKBIA may be at increased risk of developing colorectal cancer, and that the GG genotype of NFKBIA may be considered a prognostic factor for the Swedish colorectal cancer patients (5). A-708ins/ del 8 polymorphism of the promoter of the NFKBIA gene, coding the I $\mathrm{KB}$ protein, was first reported by Miterski et al, who found that the $-708 /$ del 8 polymorphism occurred with a lower frequency in primary progressive multiple sclerosis patients than in controls. This indicated that the polymorphism has an effect on the function of the IKB protein, and thereby affects the normal function of NF- $\mathrm{KB}$ (6). The aim of the present study was to investigate whether the -708ins/del8 polymorphism in the promoter region of the NFKBIA gene has an impact on the risk of colorectal cancer in a Swedish and a Chinese population, and to determine whether the polymorphism has any clinicopathological significance. The polymorphism was examined by polymerase chain reaction (PCR)-single stranded conformation polymorphism (SSCP) and DNA sequencing. 
Table I. Characteristics of the Swedish and Chinese populations.

\begin{tabular}{|c|c|c|c|c|}
\hline \multirow[b]{2}{*}{ Characteristics } & \multicolumn{2}{|c|}{ Swedish } & \multicolumn{2}{|c|}{ Chinese } \\
\hline & Patients & Controls & Patients & Controls \\
\hline Number of samples & 92 & 174 & 93 & 159 \\
\hline Males & 48 & 102 & 52 & 100 \\
\hline Females & 44 & 72 & 41 & 59 \\
\hline Mean age (years) & 73 & 55 & 58 & $48^{\mathrm{a}}$ \\
\hline Range (years) & $46-89$ & $22-77$ & $27-84$ & $19-80$ \\
\hline \multicolumn{5}{|l|}{$\mathrm{NFKB} 1^{\mathrm{b}}$} \\
\hline Wild-type & 6 & 16 & 21 & 22 \\
\hline Heterozygote & 54 & 50 & 52 & 79 \\
\hline Homozygote & 19 & 12 & 13 & 25 \\
\hline Unknown & 13 & 96 & 7 & 33 \\
\hline \multicolumn{5}{|l|}{ NFKBIA $^{c}$} \\
\hline Wild-type & 16 & 12 & 10 & 25 \\
\hline Heterozygote & 39 & 47 & 51 & 65 \\
\hline Homozygote & 22 & 27 & 27 & 69 \\
\hline Unknown & 15 & 88 & 5 & 0 \\
\hline
\end{tabular}

${ }^{\mathrm{a}}$ One unknown age; ${ }^{\mathrm{b}} 4-\mathrm{bp}$ ATTG polymorphism in the promoter region of the NFKB1 gene; ${ }^{\mathrm{c}} \mathrm{G} \rightarrow \mathrm{A}$ variation in the 3 ' UTR of the NFKBIA gene.

\section{Materials and methods}

Patients. The Swedish patients comprised 92 colorectal cancer patients (48 males and 44 females; mean age 73 years, range 46-89 years) diagnosed at University Hospital in Linköping or Vrinnevi Hospital, Sweden, between 1990 and 2000. No cases of sporadic, familial or hereditary colorectal cancer were identified. Patient gender, age, tumor location and Dukes' stage were obtained from surgical and pathology records. Tumors from the ascending and transverse colon were regarded as proximal tumors, whereas tumors from the descending, sigmoid colon and rectum were considered distal tumors. Tumor growth pattern, grade of differentiation, inflammatory infiltration and necrosis were scored by two pathologists/investigators. According to growth pattern, tumors were categorized as expansive or infiltrative type, based on the pattern of growth and invasiveness. Differentiation was graded as well-, moderately or poorly differentiated, or as mucinous/signet-ring cell carcinoma. Inflammatory infiltration was graded as weak or strong. Necrosis was determined according to the percentage of necrotic cells in each section $(<10 \%$ or $>10 \%)$. The patients underwent follow-up until 2004; 61 had died of colorectal cancer by this time.

The Chinese patients included 93 colorectal cancer patients (52 males and 41 females; mean age 58 years, one unknown age, range 27-84 years) from the Fourth Teaching Hospital of Hebei Medical University and the Tangshan Gongren Hospital, Hebei Province, China, diagnosed between 2001 and 2002. No cases of sporadic, familial or hereditary colorectal cancer were identified. Patient gender, age, tumor location, size, gross status, invasive depth, Dukes' stage and grade of differentiation were recorded by the surgeons or pathologists. Tumors from the ascending and transverse colon were regarded as proximal tumors, whereas tumors from the descending, sigmoid colon and rectum were considered distal tumors. The mean size of the tumors was $4.7 \mathrm{~cm}$ in diameter (range $1.5-13 \mathrm{~cm}$ ). Gross status was classified as polypoid and of ulcerative pattern. Invasive depth was grouped as intra- or ultra-bowel wall. Differentiation was graded as well-, moderately or poorly differentiated, or as mucinous/signet-ring cell carcinoma. Inflammatory infiltration was graded as weak or strong. Necrosis was determined according to the percentage of necrotic cells in each section $(<10 \%$ or $>10 \%)$. No information on the survival of these patients after surgery was available.

Healthy controls. The study included 174 Swedish controls (102 males and 72 females; mean age 55 years, range 22-77 years) recruited from a population-based DNA bank and 159 Chinese blood donors (100 males and 59 females; mean age 48 years, range 19-80 years) recruited from the Blood Research Centre of Hebei Province, Shijiazhuang, China. The Swedish and Chinese controls were recruited from the same residential area as their corresponding patients. They did not suffer from gastrointestinal disease or have a personal history of tumours.

The study was approved by the ethics committee at the Faculty of Health Sciences, University of Linköping, Sweden, and the Health Bureau of Hebei Province, Shijiazhuang, China.

Data regarding the 4-bp ATTG polymorphism in the promoter region of the NFKB1 gene and the $G \rightarrow A$ variation in the $3^{\prime}$ UTR of the NFKBIA gene were taken from previous studies carried out at our laboratory $(4,5)$.

Table I presents the characteristics of the Swedish and Chinese populations examined in the present study. 
DNA extraction. Genomic DNA from Swedish patients and from Chinese patients (from Tangshan Gongren Hospital) was extracted from frozen normal colorectal mucosa using the Wizard ${ }^{\circledR}$ SV Genomic DNA purification system (SDS Bioscience, Falkenberg, Sweden) according to the manufacturer's instructions. Wizard Genome Purification Profiler (SDS Bioscience) was used to extract genomic DNA from the peripheral blood of the Swedish controls and from the Chinese controls and Chinese patients (from the Fourth Teaching Hospital of Hebei Medical University).

PCR. Approximately $50 \mathrm{ng}$ of chromosomal DNA was used in a PCR reaction containing $1 \mathrm{X}$ PCR buffer (SDS Bioscience), $2.0 \mathrm{mM} \mathrm{MgCl}$ (SDS Bioscience), $0.2 \mathrm{mM}$ dNTP (VMR International, Stockholm, Sweden), $0.5 \mu \mathrm{M}$ of each primer (VMR International) and $1 \mathrm{U}$ Taq-polymerase (SDS Bioscience). The reaction mixture was diluted to $20 \mu \mathrm{l}$ per sample with distilled autoclaved water. The sequence for the forward primer was 5'-CAACAGGGCTGTTCATCC-3' and for the reverse primer 5'-CCTATACCAGGCTCTTTGC-3'. PCR was carried out in a PTC-200 (Bio-Rad Laboratories AB, Sundbyberg, Sweden). PCR conditions were: initial denaturation at $95^{\circ} \mathrm{C}$ for $5 \mathrm{~min}$; denaturation at $95^{\circ} \mathrm{C}$ for $30 \mathrm{sec}$; annealing at $64^{\circ} \mathrm{C}$ for $30 \mathrm{sec}$; and extension at $72^{\circ} \mathrm{C}$ for $30 \mathrm{sec}$ for a total of 33 cycles, followed by a final extension at $72^{\circ} \mathrm{C}$ for $5 \mathrm{~min}$. The PCR product was stored at $8^{\circ} \mathrm{C}$ until labeling.

DNA sequencing analysis. SSCP was used as a screening method to distinguish the wild-type from the deletion (-708ins/ del8). The PCR product ( $1 \mu \mathrm{l})$ was re-amplified for 12 cycles using the same protocol as above, with the addition of $[\alpha-33 P]$ dATPs instead of normal dATP. The labeled PCR products (2 $\mu \mathrm{l}$ ) were diluted with $5 \mu \mathrm{l} 0.2 \%$ sodium dodecylsulfate (SDS)/20 mM EDTA and $10 \mu$ l loading buffer [98\% formamide, 9.8 mM EDTA ( $\mathrm{pH} 8.0$ ), 0.098\% bromphenol blue and Xylene Cyanol FF]. The samples were heat-denatured, rapidly cooled and then loaded onto a 0.5X MDE-gel. Electrophoresis was performed for $12 \mathrm{~h}$ at a maximum of $4 \mathrm{~W}$. The gel was transferred to filter paper and exposed to X-ray film at $-70^{\circ} \mathrm{C}$ overnight.

DNA sequencing. DNA sequencing was used to detect the nature of the shift bands on SSCP. Powder-free gloves were used to avoid contamination. ExoSAP-IT was used to remove excess dinucleotides that would otherwise disturb the sequencing analysis. The protocol used was according to manufacturer's instructions. In brief, $5 \mu \mathrm{l}$ of PCR product was mixed with $2 \mu \mathrm{l}$ ExoSAP-IT. The total volume of $7 \mu \mathrm{l}$ was mixed and heated to $37^{\circ} \mathrm{C}$ for $15 \mathrm{~min}$, followed by inactivation of ExoSAP-IT at $80^{\circ} \mathrm{C}$ for $15 \mathrm{~min}$. DNA sequencing was performed using a MegaBACE500 Fragment Profiler (Amersham Biosciences, Little Chalfon, Buckinghamshire, UK) and a DYEnamic ET dye terminator cycle sequencing kit for the MegaBACE DNA analysis system according to the manufacturer's instructions. In brief, $3.5 \mu 1$ of ExoSAP-IT purified PCR-product was mixed with $0.25 \mathrm{mM}$ forward primer and $8 \mu \mathrm{l}$ sequencing reagent premix and diluted to a total volume of $20 \mu \mathrm{l}$ with distilled $\mathrm{H}_{2} \mathrm{O}$. Samples were run in a PCT-100 thermal cycler (Bio-Rad Laboratories $\mathrm{AB}$ ) with the following program: $95^{\circ} \mathrm{C}$ for $20 \mathrm{sec}$, $50^{\circ} \mathrm{C}$ for $15 \mathrm{sec}$ and $60^{\circ} \mathrm{C}$ for $1 \mathrm{~min}$, repeated for 25 cycles.
Table II. The -708ins/del8 polymorphism (large shift) and other mutations (small shift) in the Swedish and Chinese populations.

\begin{tabular}{|c|c|c|c|c|c|}
\hline \multirow[b]{2}{*}{ Population } & \multirow[b]{2}{*}{ No. } & \multicolumn{2}{|c|}{ SSCP } & \multicolumn{2}{|c|}{ DNA sequencing } \\
\hline & & $\begin{array}{l}\text { Large } \\
\text { shift }^{\mathrm{a}}\end{array}$ & $\begin{array}{l}\text { Small } \\
\text { shift }^{\text {a }}\end{array}$ & $-708 /$ del $^{a}$ & Mutations $^{\mathrm{b}}$ \\
\hline \multicolumn{6}{|l|}{ Swedish } \\
\hline Patients & 92 & 2 & 0 & 2 & 0 \\
\hline Controls & 174 & 8 & 0 & 8 & 0 \\
\hline \multicolumn{6}{|l|}{ Chinese } \\
\hline Patients & 93 & 0 & 3 & 0 & 1 \\
\hline Controls & 159 & 0 & 1 & 0 & 1 \\
\hline
\end{tabular}

aHeterozygote and homozygote deletion; bidentified in the area of the $-708 /$ del8 polymorphism.

\section{Results}

The polymorphism of -708ins/del8 and other mutations were examined in Swedish and Chinese colorectal cancer patients and their corresponding controls.

The -708/del 8 allele occurred with a low frequency in the Swedish population; two of the 92 Swedish patients examined and eight of the 174 controls had at least one allele with the -708/del8 polymorphism. All the SSCP shift bands had the same pattern, here called large shifts. No other mutations were found in this region among the Swedish patients or controls (Table II). Fig. 1 shows the results from SSCP and DNA sequencing analysis. In Fig. 1A, the SSCP gel shows that the $-708 /$ del8 polymorphism (d) is clearly distinguishable from the normal allele (n); Fig. 1B shows the DNA sequence of the normal allele (n), and Fig. 1C the DNA sequence of the -708/del8 polymorphism (d).

The -708/del 8 allele was absent from the Chinese population. None of the 93 Chinese patients and 159 Chinese controls analyzed had the $-708 /$ del 8 polymorphism in one or two alleles. However, four other shifts were detected by SSCP analysis among the Chinese population, here called small shifts (Table II). Three of these samples (m1-3) were from Chinese patients; one (m3) was confirmed to have a $\mathrm{T} \rightarrow \mathrm{A}$ substitution by DNA sequencing (Fig. 1D-G); another sample (m4), from the Chinese controls, had a $\mathrm{G} \rightarrow \mathrm{T}$ substitution (Fig. $1 \mathrm{H}$ and $\mathrm{I}$ ).

Table III presents clinicopathological data regarding the two Swedish patients with the $-708 /$ del8 polymorphism and the three Chinese patients with the small shift detected by SSCP analysis. Both the Swedish patients were males, diagnosed at 72 and 87 years of age, and had a heterozygote with a 4-bp ATTG deletion in the promoter region of the NFKB1 gene (4) and a heterozygote with a $\mathrm{G} \rightarrow \mathrm{A}$ variation in the $3^{\prime}$ UTR of the NFKBIA gene (5). The three Chinese patients were all females diagnosed at 52, 57 and 69 years of age. Two of these patients had a wild-type homozygote with the 4-bp ATTG deletion in the NFKB1 gene and one had a heterozygote; two of the patients had a homozygote with the $\mathrm{G} \rightarrow \mathrm{A}$ variation in the 3' UTR of the NFKBIA gene, while one was unknown. All tumors from the five patients were located in the rectum, had moderately differentiated cells, and were in Dukes' stages B or C. 
A

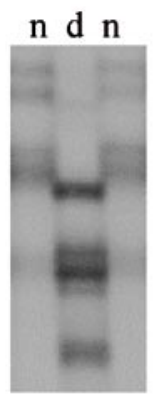

D

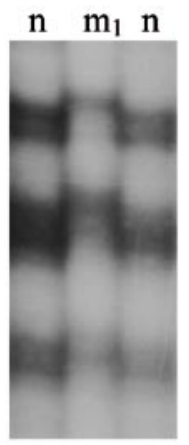

$\mathrm{H}$
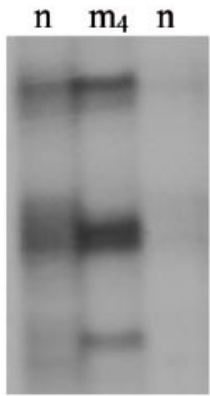

B
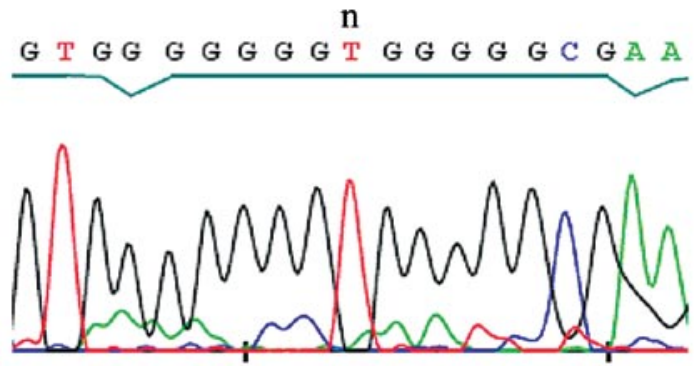

C
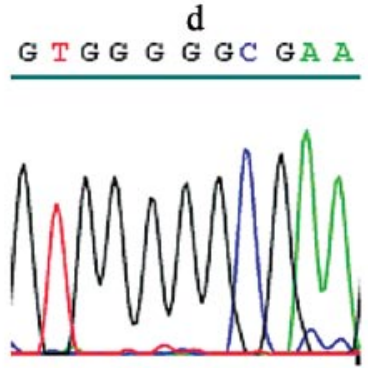

G $\mathrm{m}_{3}$

GT GG GGGGGAGGGG CGA.A

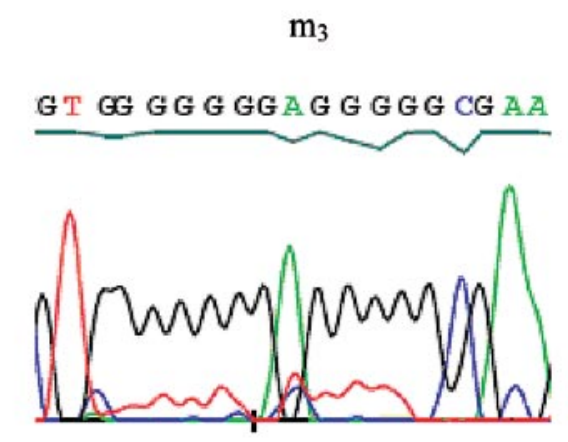

I
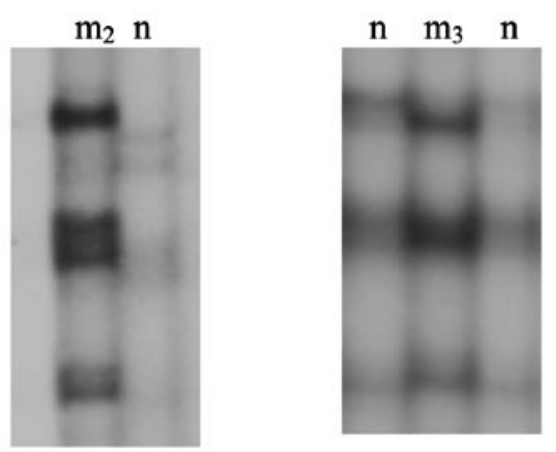

GTGGTGGGGTGGGGGCGAA

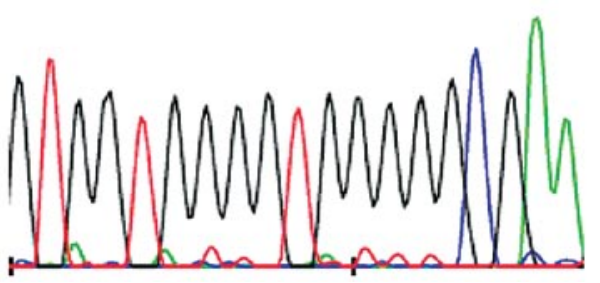

Figure 1. (A) Three samples on a single-stranded conformation polymorphism (SSCP) gel from the Swedish population, two normal (n) and one with an 8-bp deletion (-708/de18) (d) in the promoter region of the IאB $\alpha$ gene. Normal DNA sequence of (B) the promoter region and (C) -708/del8. (D and E) Two Chinese patients had similar shift bands on the SSCP gel. The third Chinese patient had (F) both shift bands on the SSCP gel and (G) a -713T $\rightarrow$ A mutation on DNA sequencing. One Chinese control had (H) SSCP bands and (I) a -718G $\rightarrow$ T mutation on DNA sequencing.

Table III. Polymorphism/mutations in the promoter region of IкB $\alpha$ in two Swedish and three Chinese patients.

\begin{tabular}{|c|c|c|c|c|c|}
\hline \multirow[b]{2}{*}{ Clinicopathological variables } & \multicolumn{2}{|c|}{ Swedish patients } & \multicolumn{3}{|c|}{ Chinese patients } \\
\hline & No. 1 & No. 2 & No. 1 & No. 2 & No. 3 \\
\hline Gender & Male & Male & Female & Female & Female \\
\hline Age (year) & 72 & 87 & 52 & 57 & 69 \\
\hline Survival (month) & 33.1 & 76.0 & Unknown & Unknown & Unknown \\
\hline Tumor location & Rectum & Rectum & Rectum & Rectum & Rectum \\
\hline Dukes' stage & $\mathrm{C}$ & B & $\mathrm{C}$ & B & B \\
\hline Differentiation & Moderate & Moderate & Moderate & Moderate & Moderate \\
\hline $\mathrm{NFKB}^{\mathrm{a}}$ & Heterozygote & Heterozygote & Heterozygote & Wild-type & Wild-type \\
\hline NFKBIA $^{b}$ & Heterozygote & Heterozygote & Unknown & Homozygote & Homozygote \\
\hline
\end{tabular}

a4-bp ATTG polymorphism in the promoter region of the NFKB1 gene; ${ }^{\mathrm{b}} \mathrm{G} \rightarrow \mathrm{A}$ variation in the $3^{\prime}$ UTR of the NFKBIA gene. 


\section{Discussion}

$\mathrm{NF}-\kappa \mathrm{B}$ is a group of proteins that are important for cell homeostasis and play a role in tumor suppression through the regulation of cell proliferation and the suppression of apoptosis (7). Disturbances in the NF- $\mathrm{KB}$ signaling pathways alter the normal cell response to many intrinsic and/or extrinsic stimuli, in many cases rendering a cell more prone to transformation into a cancer cell (8). Normal NF- $\kappa \mathrm{B}$ activity is dependent on the correct function of its inhibitory proteins, IкB (9). Therefore, the study of polymorphisms in the I $\mathrm{B}$ promoter region is of interest.

Colorectal cancer is a multifactorial disease with considerable variation in incidence worldwide (10). The reasons for this variation are still under debate, but several studies suggest that they depend on a combination of differences in polymorphism distribution and environmental factors (11). It is well known that cancer is a genetic disease, but only a small proportion of cancers follow a Mendelian pattern of inheritance (12). When lifestyle and environmental exposure change in a population, the cancer incidence alters. Migration studies reveal that the evolution of a new cancer incidence occurs within one to a few generations (13-15). It appears that environmental factors influence cancer risk by somatic mutations, while polymorphisms increase the sensitivity to environmental exposure. It is therefore of interest to investigate cancer patients from populations with varying cancer incidences. China has a relatively low colorectal cancer incidence, whereas Sweden has a high incidence (10).

We screened two groups of unselected colorectal cancer patients, one from Sweden and one from China, for a -708/del8 polymorphism in the promoter region of the NFKBIA gene. We also screened two groups of healthy controls recruited from the same residential areas as their corresponding patients. The results showed that the polymorphism was very rare in the Swedish population studied. Only 2.2\% (2/92) of the Swedish patients and $4.6 \%(8 / 174)$ of the Swedish controls had the $-708 /$ del 8 polymorphism in one or more alleles. The numbers were too low to carry out statistical analysis, so no conclusions could be drawn regarding whether the polymorphism increases the risk of colorectal cancer in the Swedish population. We did not continue to genotype more samples since the polymorphism was found to be so rare. The only conclusion we can draw is that the polymorphism most likely does not have a potential effect on the incidence of colorectal cancer due to its rare occurrence. None of the Chinese patients or controls in the study had the $-708 / \mathrm{del} 8$ polymorphism. We could not exclude the limited sample number of the present study as a reason for the low frequency of detection of the polymorphism; however, it appears that the polymorphism is not a risk factor for colorectal cancer in the two populations.

Instead of the -708/del8 polymorphism, we found four small shift band mutations in three Chinese patients and in one Chinese control. One of the mutations in the Chinese patients was a $\mathrm{T} \rightarrow \mathrm{A}$ single nucleotide substitution. The mutation in the Chinese control was a $\mathrm{G} \rightarrow \mathrm{T}$ substitution. It was not possible to identify the two other shifts on SSCP gel by DNA sequencing.
Table III lists the clinicopathological factors investigated in the patients with a polymorphism or a mutation. There is a detectable age difference between the two Swedish patients (72 and 87 years of age) and the three Chinese patients (52, 57 and 69 years of age), though this age difference exists between the populations studied. Another difference is that both the Swedish patients were male, while the three Chinese patients were female. There are, however, some similarities between the patients of the two populations. The tumors were all located in the rectum, and the tumor cells were classified as moderately differentiated. When compared with two other polymorphisms examined in the same samples as those used in the study, both the Swedish patients were found to have a heterozygote with a 4-bp ATTG deletion in the promoter region of the NFKB1 gene and a heterozygote with a $\mathrm{G} \rightarrow \mathrm{T}$ substitution in the promoter region of the NFKBIA gene. The case was not the same for the three Chinese patients compared to the Swedish patients: for the 4-bp ATTG deletion in the promoter region of the NFKB1 gene, two of the Chinese patients had a wild-type homozygote and one had a heterozygote; two patients had a homozygote with a $\mathrm{G} \rightarrow \mathrm{T}$ substitution in the promoter region of the NFKBIA gene and one was unknown. There is insufficient evidence to prove that these polymorphisms/mutations have any functional interactions.

The 8-bp polymorphism was first reported by Miterski et al, who found that the $-708 /$ del 8 polymorphism occurred with lower frequency in primary progressive multiple sclerosis patients than in controls (6). The authors found four different alleles, two different 8-bp insertions and one 8-bp deletion in addition to the normal allele (personal communication); we were only able to identify two of these alleles in our sample, the normal allele (so-called due to the fact that it was the most common allele in our sample; its frequency in the study performed by Miterski et al is unknown, and it is not necessarily normal in function) and the 8-bp deletion. Miterski et al found other polymorphisms in the promoter region of the NFKBIA gene; however, these showed no significant correlation with the disease (6). Klein et al (16) investigated another of the polymorphisms reported by Miterski et al, a $-420 \mathrm{c} / \mathrm{g}$ substitution in the promoter region of NFKBIA, but found no significant relationship to Crohn's disease.

In conclusion, the $-708 /$ del 8 polymorphism was found to be rare in the examind Swedish population and absent in the Chinese population, indicating that the polymorphism is not a main risk factor for colorectal cancer incidence in the two populations. However, it is of interest to note that the -708/ del8 polymorphism was found only in the Swedish and not in the Chinese population. In contrast, the other mutations were found only in the Chinese population but not in the Swedish population. These results indicate that there is a difference between the two populations regarding the polymorphism and mutations examined in this study.

\section{Acknowledgements}

This study was supported by grants from the Swedish Cancer Foundation and the Health Research Council in the South-East of Sweden. 


\section{References}

1. Hoffmann A, Levchenko A, Scott ML and Baltimore D: The IкB $\mathrm{NF}-\kappa \mathrm{B}$ signaling module: Temporal control and selective gene activation. Science 298: 1241-1245, 2002.

2. Hayden MA and Ghosh S: Signaling to NF-кB. Genes Dev 18: 2195-2224, 2004.

3. Domingo-Domenech J, Oliva C, Rovira A, Codony-Servat J, Bosch M, Filella X, Montagut C, Tapia M, Campás C, Dang L, Rolfe M, Ross JS, Gascon P, Albanell J and Mellado B: Interleukin 6, a nuclear factor- $\mathrm{kB}$ target, predicts resistance to docetaxel in hormone-independent prostate cancer and nuclear factor- $\mathrm{\kappa B}$ inhibition by PS-1145 enhances docetaxel antitumor activity. Clin Cancer Res 12: 5578-5586, 2006.

4. Lewander A, Butchi A, Gao J, He LJ, Lindblom A, Arbman G, Carstensen J, Zhang ZY, The Swedish Low-risk Colorectal Cancer Study Group and Sun XF: Polymorphism in the promoter region of the NFKB1 gene increases the risk of sporadic colorectal cancer in Swedish but not in Chinese populations. Scand J Gastroenterol 42: 1332-1338, 2007.

5. Gao J, Pfeifer D, He LJ, Qiao F, Zhang Z, Arbman G, Wang ZL, Jia CR, Carstensen J and Sun XF: Association of NFKBIA polymorphism with colorectal cancer risk and prognosis in Swedish and Chinese populations. Scand J Gastroenterol 42: 345-350, 2007.

6. Miterski B, Böhringer S, Klein W, Sindern E, Haupts M, Schimrigk S and Epplen JT: Inhibitors in the NF- $\kappa \mathrm{B}$ cascade comprise prime candidate genes predisposing to multiple sclerosis, especially in selected combinations. Genes Immun 3: 211-219, 2002.
7. Mayo MW and Baldwin AS: The transcription factor NF- $\mathrm{kB}$ : control of oncogenesis and cancer therapy resistance. Biochim Biophys Acta 1470: 55-62, 2000.

8. Karin M, Cao Y, Greten FR and Li ZW: NF- $\kappa B$ in cancer: from innocent bystander to major culprit. Nat Rev Cancer 2: 301-310, 2002.

9. Ghosh S, May MJ and Kopp EB: NF- $\mathrm{kB}$ and REL proteins: evolutionary conserved mediators of immune responses. Ann Rev Immunol 16: 225-260, 1998.

10. Parkin DM: International variation. Oncogene 23: 6329-6340, 2004.

11. Kolonel LN, Altshuler D and Henderson BE: The multiethnic cohort study: exploring genes, lifestyle and cancer risk. Nat Rev Cancer 4: 519-527, 2004

12. Mucci LA, Wedren S, Tamimi RM, Trichopoulos D and Adami O: The role of gene-environment interaction in the rtiology of human cancer: examples from cancers of the large bowel, lung and breast. J Intern Med 249: 477-493, 2001.

13. Geddes M, Balzi D, Buiatti E, Khlat M and Parkin D: Cancer in Italian migrants. Cancer Causes Control 2: 133-140, 1991.

14. Iscovich J and Howe GR: Cancer incidence patterns (1972-91) among migrants from the Soviet Union to Israel. Cancer Causes Control 9: 29-36, 1998.

15. Maskarinec G and Noh JJ: The effect of migration on cancer incidence among Japanese in Hawaii. Ethn Dis 14: 431-439, 2004.

16. Klein W, Tromm A, Folwaczny C, Hagedorn M, Duerig N, Epplen JT, Schmeigel WH and Griga T: A polymorphism of the NFKBIA gene is associated with Crohn's disease patients lacking a predisposing allele of the CARD15 gene. Int J Colorectal Dis 19: 153-156, 2004. 